\title{
El abolicionismo transnacional cubano: los relatos antiesclavistas de Félix Tanco y uel tiempo de la nación»"
}

\author{
ADRIANA MÉNDEZ RODENAS
}

The University of Iowa

\begin{abstract}
Adriana Méndez Rodenas
Catedrática de literatura hispanoamericana y literatura comparada en la University of Iowa. Especialista en la escritura de viajes, estudios transatlánticos, y caribeños, su último libro, Transatlantic Travels to Nineteenth Century Latin America: European Women Pilgrims (2013), estudia los relatos de viaje de viajeras europeas a América Latina antes y después de la Independencia. Editó un número sobre viajeras europeas para la revista Review publicada por Americas Society de Nueva York. Recuperó la importante figura de la condesa de Merlin para las letras cubanas en su Gender and Nationalism in Colonial Cuba-The Travels of Santa Cruz y Montalvo, Condesa de Merlin (1998). Actualmente investiga la ecología del Caribe a través de diversos géneros literarios y artísticos.
\end{abstract}

\section{RESUMEN}

Momentos antes de que el cónsul británico Richard Madden partiera para Inglaterra en 1839, Domingo del Monte le entrega un portfolio de obras escritas por miembros de su tertulia en apoyo a la causa abolicionista. Este evento se va a convertir en uno de los capítulos mas intrigantes de la historia literaria caribeña. Este ensayo examina el encuentro entre Del Monte y Madden a la luz del abolicionismo transnacional cubano. Después de trazar las redes entre la primera generación de escritores cubanos y los abolicionistas ingleses, y cómo éstas influyeron en su misión ideológica, se pasa a analizar los relatos antiesclavistas de Félix Tanco, y particularmente el titulado “"Un niño en La Habana”». Al trasladar el debate sobre la esclavitud a la esfera privada, Tanco dramatiza el impacto psicológico de la relación amo/esclavo. Al final, se considera cómo éstas y otras obras abolicionistas contribuyen al «tiempo de la nación» a mediados del siglo XIX cubano.

Palabras clave: Abolicionismo, narrativa, Félix Tanco, Richard Robert Madden.

\section{ABSTRACT}

Moments before British consul Richard Madden was to leave for England in 1839, Domingo del Monte handed him a portfolio of literary works written by members of his tertulia to garner sympathy for the abolitionist cause. This event will become one of the most intriguing chapters in Caribbean literary history. This paper examines the exchange between Del Monte and Madden in light of the international context of Cuban abolitionism. After showing how the ties between the first generation of Cuban writers and English abolitionists affected their collective sense of purpose, the article analyzes Félix Tanco's anti-slavery tales, and specifically the one titled «Un niño en La Habana». By shifting the debate on slavery to the domestic sphere, Tanco dramatizes the psychological effects of the master/slave relationship. The paper ends by considering how these anti-slavery works contribute to the «time of the nation» in mid-19th century Cuba.

Keywords: Abolitionism, narrative, Félix Tanco, Richard Robert Madden. 


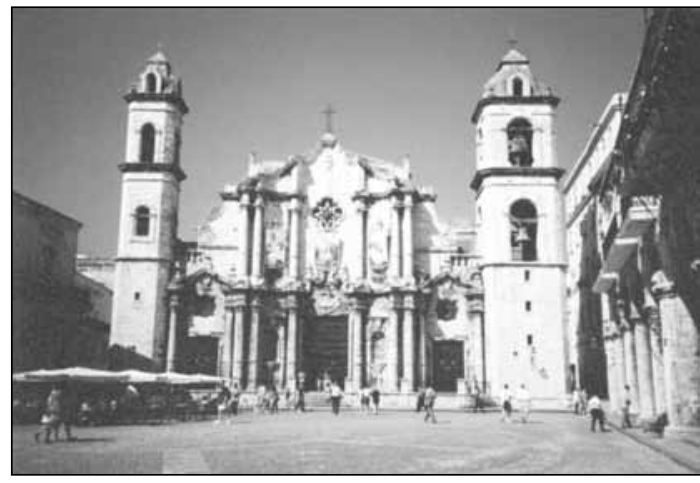

Catedral de La Habana. Fotografía de José Gomariz.
1. El abolicionismo transnacional cubano: El círculo de Domingo del Monte y los abolicionistas ingleses

Uno de los episodios más intrigantes de la historia literaria caribeña es el encuentro entre Domingo del Monte y el abolicionista irlandés Richard Robert Madden que tomó lugar en el puerto de La Habana en 1839. Con gesto cauteloso para evitar la sospecha de las autoridades coloniales, en ese momento Del Monte le hace entrega al cónsul británico de un álbum literario compuesto de una serie de obras clandestinas escritas por los miembros más destacados de su círculo literario. Bajo el ojo vigilante de la censura española, las obras, imposibles de publicar en Cuba, se destinaban a un público europeo con miras a conseguir apoyo internacional para la resistencia pasiva que Del Monte y sus seguidores habían montado contra el sistema esclavista. Vocero del temprano abolicionismo promulgado por Del Monte, el álbum contenía obras canónicas de la literatura cubana: desde Autobiografía de un esclavo de Juan Francisco Manzano hasta la novela sentimental Francisco: el ingenio o las delicias del campo de Anselmo Suárez y Romero, texto fundacional de la narrativa antiesclavista. Hallazgo realizado por Adriana Lewis Galanes en la Biblioteca Nacional de Madrid, el álbum, oculto adentro de un dossier de cartas escritas por el cuáquero inglés Benjamin Barron Wiffen al bibliófilo español Luis Usoz y Río, contenía otros dos textos fundamentales de esta tradición: el segundo relato de «Escenas de la vida privada en la isla de Cuba,» parte de un tríptico narrativo escrito por el matancero Félix Tanco y Bosmeniel para denunciar los excesos de la institución esclavista, y «El ranchador,» dramático relato de Pedro José Morillas que narra la captura de esclavos cimarrones (Lewis Galanes 257, 263-264; Luis [1990] 36-37). No obstante, la novela de Suárez y Romero y los relatos de Tanco y de Morillas se quedaron atrás en un archivo hasta muy recientemente recuperado (Lewis Galanes 259, 260; Luis [1990], 37). Si bien «El ranchador» se publicó en 1856, diecisiete años después de que se incluyera en el álbum, la novela Francisco de
Suárez y Romero se publicó póstumamente en 1880 (Kutzinski 19). En cambio, las «Escenas privadas en la isla de Cuba» de Tanco tuvieron que esperar casi un siglo después y, aún así, aparecieron solo en forma trunca en el número 1925 de la revista Cuba contemporánea (Lewis Galanes 262).

En lo que sigue, quisiera, primero, deslindar el contexto internacional del abolicionismo cubano, especialmente en lo que concierne los vínculos entre la primera generación de escritores cubanos y los abolicionistas ingleses. Aunque se ha analizado con atención la representación literaria de la esclavitud, no se ha determinado a ciencia cierta si el abolicionismo cubano fue un movimiento autónomo o hasta qué grado cobró impulso gracias a las corrientes abolicionistas europeas. La segunda parte del ensayo aborda la narrativa de Félix Tanco y Bosmeniel, considerado el más radical de los abolicionistas cubanos, y el aporte de sus «mini-relatos» al debate sobre la esclavitud. Se analizará el casi olvidado cuadro «Un niño en La Habana,» ya que traslada el debate sobre los efectos de la esclavitud desde la esfera pública a la privada. Al colocar la preocupación por la suerte de los esclavos adentro del hogar de la sacarocracia, Tanco resalta, de manera paradójica y frontal, tanto la urgencia del debate sobre el sistema esclavista, como la vulnerabilidad de la primera generación de criollos ilustrados ante el espectador extranjero.

A la víspera de su salida de La Habana, el irlandés Madden, quien fungía en ese entonces como cónsul británico, se refiere a este álbum con sentidas palabras. En una carta de despedida dirigida a Domingo Del Monte el 23 septiembre, 1838, Madden sella su compromiso tanto con el círculo de Del Monte como con su declarado abolicionismo:

This last token of your friendship I prize more than I can tell you-its external beauty and the extreme neatness of the penmanship [...]-if anything were wanting to make a token of your remembrance very dear to me cannot fail to recommend your album to $\mathrm{me}$ [sic] and to cause me only one regret that I find no composition there of yours (Del Monte [1930] 4: 86).

El tono emotivo de esta carta esconde lo que debería haber sido el propósito compartido de ambos: «la recopilación de obras literarias que reflejaran la real situación de los esclavos en Cuba para apoyar la campaña 
abolicionista que propugnaba el gobierno inglés» (Bueno 171).

Volvamos nuevamente al intercambio silencioso sostenido en el puerto de La Habana. Aunque el misterio acerca del contenido del álbum ya se ha resuelto, no así el criterio que rige la selección de textos, problema más agudo si consideramos que Del Monte se los entrega a Madden para que él los presentara ante la convención antiesclavista a celebrarse en Londres el siguiente año (Luis [1990] 97; Burton, 83). Sabemos que Madden publicó su propia traducción de los poemas de Manzano bajo el título Poems by a Slave in the Island of Cuba, al igual que una versión de su autobiografía titulada Life of a Negro Poet en 18401. La publicación en inglés de la Autobiografía de Manzano apunta a un vínculo más estrecho: el establecido entre Madden como sujeto marginal en Gran Bretaña debido a su origen irlandés, y el objeto de su estudio, Juan Francisco Manzano, esclavo relegado a las afueras de la sociedad colonial cubana. Gera C. Burton argumenta que los lazos establecidos entre Madden y Manzano constituyen un caso de dos sujetos aliados e identificados en un frente común contra sistemas opresivos (50). Médico de profesión, Madden dejó su carrera al ser asignado como Magistrado Especial del gobierno británico en Jamaica (1833-1834), experiencia que le sirvió para adherirse a la causa a favor de la libertad de los esclavos al igual que de su patria (Burton, 74, 50). Ya convertido en ardiente defensor de la causa abolicionista, Madden llegó a La Habana como Superintendente de los Africanos Libertos; su misión oficial era hacer cumplir los reglamentos del tratado de 1835 entre España y Gran Bretaña que proponía la elimación de la trata ilegal, fin que se llevaría a cabo mediante la captura de barcos negreros. Uno de los puntos más polémicos de este tratado giraba en torno a la suerte de los emancipados, africanos liberados, quienes, una vez atrapados los barcos negreros, eran destinados a las islas británicas (Murray [1980] 120). Como árbitro de las Comisiones Mixtas, Madden debería garantizar el traslado de los esclavos liberados hacia las islas vecinas bajo control anglosajón (Murray [1980] 121; Luis [1990] 35-36). Madden permaneció en Cuba tres años (1836-1839), período durante el cual se involucra con los tempranos abolicionistas y el círculo delmontino, al igual que ejerce funciones diplomáticas en medio de un ambiente cargado de tensiones (Burton 77-78)2.

Las discrepancias entre España y Gran Bretaña se agudizan por la presencia, que para las autoridades españolas resultó provocadora, del barco Romney que los británicos anclaron abiertamente en el puerto de La Habana en agosto, 1837; el Romney serviría

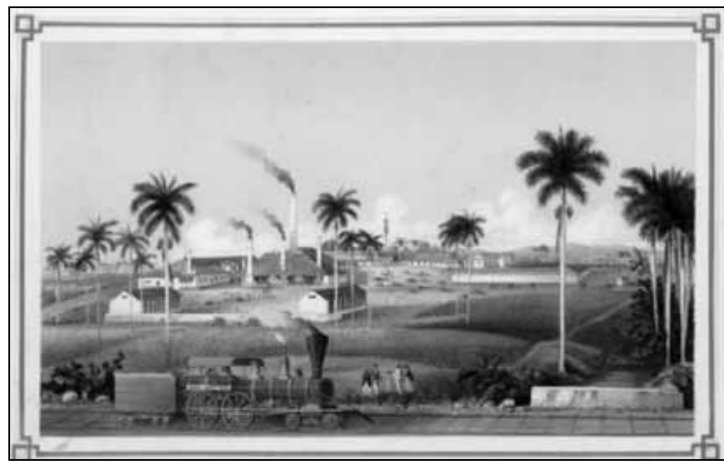

Ingenio Acana. Matanzas. Propiedad de José Eusebio Alfonso. Eduardo Laplante. Los ingenios (1857) de Justo Germán Cantero. como lugar de refugio provisional para los emancipados (Murray [1980] 123). Primero Madden y, después, su sucesor, el más volátil David Turnbull, eran, a ojos de la administración colonial, agentes subversivos, ya que su declarado abolicionismo amenazaba no solamente la estabilidad y seguridad de la isla, sino el caudal proveído por la trata ilegal esclavista (Murray [1980] 121)3. Es por eso que el Capitán General Miguel Tacón consideró a Madden «"un hombre peligroso"» pues subvertía la supuesta «felicidad» de la isla, eufemismo con que se denominaba la bonanza económica derivada del sistema esclavista (Murray [1972] 49; Burton 94). En breve, la complicidad de la clase hacendada criolla y del gobierno colonial con la trata se debe a tres factores no por relacionados menos contradictorios: el aumento dramático de la producción azucarera que requiría un número creciente de mano de obra esclava; la transformación de la industria azucarera a partir del ingenio mecanizado o factoría, y el temor a la rebelión que había debilitado la economía de plantación en Saint Domingue ${ }^{4}$. Este complejo de causas obligó a España a obviar el tratado con Inglaterra y explica por qué la trata ilegal esclavista se prolongó hasta la década de 1860 (Murray [1980] 298-299).

El intercambio de ideas entre Madden y Domingo Del Monte, documentado ampliamente en el Centón Epistolario, prueba que Del Monte alentó el contacto entre los escritores de su círculo, especialmente Félix Tanco y Bosmeniel, y el cónsul británico, poniéndolos al tanto de las ideas, consideradas radicales, del irlandés. Este estrecho vínculo comprueba que los voceros del protoabolicionismo cubano y los ingleses compartían un ideario común. A pesar de su simpatía por el irlandés, David Murray concluye, en cambio:
Anselmo Suárez y Romero corrige y edita el manuscrito de Manzano, versión que Madden adaptó para un público inglés. Para un detallado e intrigante recuento de las múltiples versiones de la Autobiografía de Manzano, véase Luis [2007] 18-20 y [1990] 35-36.

2

Para un resumen de la misión de Madden en La Habana, y de su eventual despedida al servicio del gobierno británico por denunciar la complicidad de los ingleses en la trata, véase Burton (73-82).

3

Para un recuento detallado de la captura de los barcos negreros en las costas de Cuba, véase Leví Marrero 9: 54-62.

Moreno Fraginals explica tanto las causas como las consecuencias de la transición a la gran factoría en el capítulo II de EI ingenio 1: 39-102.

El abolicionismo transnacional cubano: los relatos antiesclavistas de Félix Tanco y «el tiempo de la nación"

ADRIANA MÉNDEZ RODENAS 
5

Para un recuento de las conexiones entre Del Monte y los abolicionistas ingleses, véase Luis [1990] 2-3, 12-18, 27-39.

6

Adapto aquí el tan sugestivo término de Homi Bhabha que articula la dimensión histórica del nacimiento de una nación en términos de un tiempo y destiempo desacompasado bajo el peso del colonizaje. Justamente, Tacón se aprovecha del «decreto de las facultades omnímodas de 1825 que autorizaba al jefe superior de Cuba a gobernar la Isla bajo las condiciones de una plaza sitiada» (Leví Marrero 9: 53). Sugiero que el impacto del mandato opresivo de Tacón provoca «el tiempo de la nación» tal como se expresa por escritores como Tanco.

7

Burton comenta igualmente la importancia de la encuesta, publicada por la Sociedad antiesclavista británica junto con parte de la versión inglesa de los poemas de Manzano hecha por Madden (83). Junto al documento sobre la trata ilegal, el álbum entregado a Madden contenía otro interrogatorio más largo sobre «el estado eclesiástico» de la isla con fecha de septiembre, 1839 (Lewis Galanes 265). Quizás por eso Burton llega a la conclusión acerca de la ambivalencia de Del Monte (83). En lo que sigue, espero mostrar que Del Monte estuvo a la altura de las circunstancias.

El abolicionismo transnaciona cubano: los relatos antiesclavistas de Félix Tanco y «el tiempo de la nación"

ADRIANA MÉNDEZ RODENAS
Saco in Europe and his fellow creoles in Cuba, notably Domingo del Monte, thus had little in common with British abolitionists like Madden and later David Turnbull except a mutual hatred of the slave trade [...]. Their co-operation could never be close, certainly there could not be any fusion into a unified abolitionist movement combining Cuban creoles and British abolitionists. ([1980] 131)

Aunque útil para la investigación historiográfica, la separación tajante que hace Murray entre reformistas cubanos y extranjeros requiere mayor precisión. Para eso, es necesario repasar el contexto represivo en que se produjeron las obras contenidas en el álbum.

El nacimiento de la narrativa antiesclavista cubana se relaciona directamente con este cargado contexto histórico ${ }^{5}$. En vísperas del tratado de 1835, llegó a Cuba el nuevo Capitán-General, Miguel Tacón (1834-1838), cuyo "profundo resentimiento y desconfianza hacia los criollos» lo llevó a suprimir las primeras expresiones de una cultura nacional (Leví Marrero 9: 53). Cuando José Antonio Saco publica en 1832 un artículo "contra los negreros y prestamistas españoles,» se suscita un debate público sobre «la liquidación total de la trata» que tuvo enormes repercusiones para «el tiempo de la nación» (Benítez Rojo $207)^{6}$. Saco y sus seguidores - principalmente José de la Luz y Caballero y Domingo del Monte - habían intentado crear «una Academia de Literatura Cubana independiente de la Sociedad Patriótica», institución controlada por los intereses peninsulares y la sacarocracia (Benítez Rojo 208). En1834, Tacón disolvió la Academia, clausuró la prestigiosa Revista Bimestre Cubana, y mandó a Saco al exilio, sucesos que, en su conjunto, representaron «el primer esfuerzo organizado de los intelectuales cubanos para constituir un foco de Resistencia frente al poder de los negreros y la sacarocracia» (Benítez Rojo 209). Al siguiente año, Domingo Del Monte trasladó el círculo literario de Matanzas hacia La Habana (Luis [1990] 34). Bajo su mecenazgo, los escritores cubanos recién formados, como Tanco y Suárez y Romero, lograron articular la primera expresión del sentimiento nacionalista, contradiciendo el poder de peninsulares y comerciantes involucrados en la trata negrera con una serie de escritos ideológica y estéticamente cargados, que, aún hoy en día, impresionan por la calidad casi profética de sus enunciados.
Estas circunstancias nos ayudan a entender lo que realmente ocurrió en ese intercambio secreto entre Del Monte y Madden en el puerto de La Habana, cuando el primero le entrega sigilosamente el contenido del álbum. Dado que las autoridades españolas aplastaban cualquier discusión pública sobre el polémico asunto de la esclavitud, Del Monte encargó la mayoría de las obras antiesclavistas a ser publicadas en el extranjero (Luis [1990] 36-37). Al entregarle prácticamente todo el trabajo acumulado de la tertulia a Madden, Del Monte pensaba cumplir un doble propósito: para el público ilustrado en Europa, solicitaba apoyo para la causa abolicionista por la que luchaban los reformistas criollos, acudiendo particularmente a los abolicionistas ingleses (Lewis Galanes 265); dentro de Cuba, el líder de la tertulia encabezaba un movimiento contestatario a la autoridad colonial y a la institución esclavista por medio de la letra escrita (Luis [1990] 27-28, 32). Este es el momento en que se urde lo que el notable crítico Antonio Benítez Rojo llama «la Conspiración del Texto» (208): el surgimiento de un discurso que entreteje letra y política, y en el que Félix Tanco va a cumplir una función de avanzada.

Parte de esta conspiración implica el sostenido e intenso diálogo entre Del Monte y Madden antes y después de la entrega del álbum literario en 1839 y que involucra al criollo dentro del discurso abolicionista. Con fecha del 17 de septiembre, 1839, Del Monte responde con lujo de detalles a un cuestionario o encuesta sobre el negocio ilegal de esclavos que le había presentado el mismo Madden7. Este documento, copiado en la edición de Madden de los poemas de Manzano, Poems by a Slave in the Island of Cu$b a$, y recogido asimismo en los Escritos de Del Monte, contenía también valiosos testimonios acerca de las estadísticas y el cuadro demográfico de la población esclava de la isla, al igual que otros datos pertinentes como el desequilibrio demográfico entre hombres y mujeres en los ingenios, la alta tasa de mortandad de la población esclava, inclusive los precios establecidos para cada tipo de esclavos, conforme edad, género y condición física (Del Monte [1929] 133-135). Del Monte también le ofreció a Madden datos detallados sobre la forma en que se conducía la trata ilegal; por ejemplo, el tránsito y condiciones de los barcos negreros que entraban en el puerto de La Habana, el tipo de barco que se utilizaba en el tráfico de esclavos, las ganancias y pérdidas que incurrían los nefastos comer- 
ciantes al transportar la carga humana desde África, hasta el detalle del uso de la bandera portuguesa para ofuscar a los vigilantes de las comisiones extranjeras durante la travesía por el Atlántico (Del Monte [1929] 137-138; citado en Leví Marrero 9: 68-69). El informe mostraba también la duplicidad del discurso abolicionista internacional, ya que indicaba no sin dejo de ironía que los bienes dados en intercambio por los esclavos africanos se manufacturaban en Gran Bretaña; por ejemplo, los agarres de hierro y otros instrumentos de tortura empleados a bordo para controlar a los desafortunados atrapados adentro del barco (Del Monte [1929] 136). El testimonio de Del Monte no paraba ahí, sino que continuaba con una condena abierta a la complicidad de la administración colonial española con el tráfico ilegal, al punto de detallar el porcentaje exacto del pago que se acostumbra dar a los oficiales españoles para asegurar su silencio, junto con la tasa de ganancia entregada al Capitán General Tacón durante los cuatro años de su gobierno - un total extravagante de 450,000 pesos (citado en Leví Marrero 69). En las atinadas si bien a ratos obsesivas respuestas a la encuesta de Madden, Del Monte hizo hincapié en cómo España, si bien ratificó el decreto según la letra de la ley, en la práctica dejó de cumplirlo en las colonias de ultramar, tal como se prueba en el siguiente diálogo:

$-¿$ Tiene el gobierno español poder suficiente para suprimirlo? [la trata negrera]

-Sobradísimo.

- ¿Tiene deseos de suprimirlo? -Ninguno.» (Del

Monte, [1929] 142-143; citado en Leví Marrero, 9: 69).

Los historiadores confirman que Madden sacó gran provecho de estos datos en su comparecencia frente la Convención Antiesclavista Británica (British Anti-Slavery Convention) que tomó lugar en 1840 (Murray [1980] 131).

Unos cuantos meses antes, en junio de 1838, Madden había recibido otro documento sobre la suerte de los emancipados, escrito por Tanco, quizás como adelanto del informe más detallado de Del Monte. La admiración que Madden disfrutaba entre la primera generación de escritores cubanos se advierte en la carta del 28 junio de 1838 que Tanco le escribe a Del Monte para asegurarse de que Madden había recibido el informe, dado que se trataba de un documento tan políticamente cifrado: «Grande satisfaccion será para mi que este Sor. apruebe mis ideas; que las encuentre quizás conformes con las suyas, que desde luego supongo las mas arregladas respecto á colonias siendo él inglés, que vale tanto como decir sabio [...]» (Del Monte [1957] 7:107) .

El arribo de David Turnbull en su doble capacidad como cónsul británico y jefe de la comisión mixta (Murray [1980] 141, 149) abre una segunda etapa en el desarrollo del temprano abolicionismo cubano. Fue justamente Madden quien primero presentó David Turnbull a Del Monte en 1838. Apasionado vocero de la liberación de los africanos esclavizados, Turnbull llegó a Cuba noviembre, 1840 con el plan de ampliar los poderes jurídicos de las comisiones mixtas, lo que permitiría a los esclavos presentar sus demandas y agravios a cuenta propia (Murray [1980] 135, 141-142, 146-149). Las autoridades españolas tratatron de suprimir lo que ellos consideraban las actividades peligrosamente subversivas de Turnbull, su tendencia a alentar rebeliones de esclavos, a tal grado que, con el ánimo de callar sus escandalosas ideas, decidieron someterlas a un debate público. En apoyo a la defensa de Turnbull, Del Monte presentó un alegato que exponía las razones por las cuales se prolongaba todavía el negocio ilegal, tomando partida no solo con el cónsul británico, sino exponiéndose a un riesgo mayor, al declarar públicamente su repudio a la administración colonial (Murray [1980] 149). Cuando a Turnbull lo expulsaron de la prestigiosa Sociedad Económica de Amigos del País, Del Monte y otros escritores cubanos firmaron una protesta exigiendo que se revocara esta drástica medida (Murray [1980] 151). No obstante los límites a la abierta discusión sobre el abolicionismo en aquella época, los escritores del círculo de Del Monte estaban profundamente comprometidos con la causa antiesclavista. La red de contactos clandestinos resumidos aquí sugiere que Del Monte y sus seguidores usaron a los abolicionistas ingleses para dar voz pública a la posición ideológica que, de otra forma, les era prohibido expresar.

De forma paralela, la presencia de los abolicionistas ingleses en Cuba tuvo gran impacto en las actividades literarias del círculo delmontino. En una carta escrita a Del Monte el 2 de julio de 1838, Madden reconoce su inclinación hacia la literatura y declara además: «I love literature for its own sake-and I would have every one love it for its bumanizing effects in all places it matters not where.» (Del Monte [1926] 3:168; énfasis del autor) ${ }^{9}$. En Cuba, sin En su carta, Tanco contrasta el sistema colonial británico con el español, caracterizando al primero de "acertado y racional,»y, al segundo, de "bárbaro y absurdo» (Del Monte [1957] 7:107).

9

«Amo la literatura por su propia virtud y la amo por sus efectos humanizadores en cualquiera parte donde se estudie [...].» (Traducción en Del Monte [1926] 3: 170).

El abolicionismo transnaciona cubano: los relatos antiesclavistas de Félix Tanco y «el tiempo de la nación"

ADRIANA MÉNDEZ RODENAS 
10

Para un análisis de la novela desde el punto de vista del «deseo triangular,》 véase Luis (4649).

El abolicionismo transnaciona cubano: los relatos antiesclavistas de Félix Tanco y «el tiempo de la nación»

ADRIANA MÉNDEZ RODENAS embargo, la práctica escritural tenía que cumplir un propósito más didáctico que estético:

Now as I know no atrocity so likely to render men «feros» as stealing men, or buying stolen men-[...] where that monstrous Incubus the slave trader hung over the morals of any land-there could be no guarantee for public faith [sic] no security for liberty - no permanence for prosperity [sic] no field for pure religion [...]-and, no extensive influence to be hoped for Literature where it was not permitted to grapple with a Monster that rears aloft its many headed iniquity and for all evil is omnipotent. (Del Monte [1926] 3:168-169)

Ahora bien; como yo no sé de otra atrocidad que mas contribuya á hacer fieros los hombres, como es la de robar hombres, ó comprar hombres robados, aseguré á V. que, donde aquel monstruo infernal (el tráfico de esclavos) ahoga la mortalidad de cualq. ${ }^{\mathrm{r}}$ pais, no puede haber garantia $\mathrm{p}^{\mathrm{a}}$ la fé publica-ni fianza $\mathrm{p}^{\mathrm{a}}$ libertad-ni permanencia $\mathrm{p}^{2}$ la properidad, ni campo $\mathrm{p}^{\mathrm{a}}$ una religion pura $[. .$.$] ni hay que esperar q. { }^{\mathrm{e}} \mathrm{la}$ literatura ejerza un influjo extenso, donde no es lícito luchar con una hidra que levanta impune sus mil inícuas cabezas y es omnipotente $\mathrm{p}^{\mathrm{a}}$ todo mal. (Del Monte [1926] 3 : 170; ortografía original).

A pesar de que como «estranjero y [...] empleado de un gobierno estranjero,» Madden se frenó de declarar abiertamente su verdadera opinión acerca de la esclavitud, sí concluyó, aunque no tan «discreta y prudentemente» como le convenía a su rango, que "He that shall steal a Man and sell him being convicted of the guilt shall be put to death!!!» [«El que robase á un hombre y lo vendiese siendo convencido de su delito, muriese p.r ello!!!»] (Del Monte [1926] 3:169; traducción 170; énfasis del autor; citado en Luis [1990] 38).

Además de estos comentarios acerca del impacto social de la literatura, en otra carta dirigida Del Monte (sin fecha, pero probablemente escrita en septiembre de 1839), Madden ofreció una valoración sobre la novela Francisco de Suárez y Romero, obra que suscitó amplia discusión entre los escritores cubanos por su franca representación de las relaciones interraciales entre amos y esclavas; más precisamente, por revelar las desigualdades de género y poder que caracterizaban a la erótica de la nación (Del Monte [1930] 4: 83-84). Obra emblemática de la narrativa antiesclavista cubana, Francisco se considera una novela sentimental dado el triángulo amoroso urdido entre
Ricardo, el joven amo sin principios ni moral, la esclava doméstica Dorotea, una mulata enamorada del noble Francisco, y el protagonista, quien trabajaba de sol a sol en los cañaverales y estaba dispuesto a sufrir los extremos del castigo físico como consecuencia de su amor ${ }^{10}$. $\mathrm{Al}$ referirse al eje típicamente romántico de la obra, Madden critica la opinión de José Antonio Saco, quien, al emitir su juicio sobre la esclavitud, expresaba «any thing he did not think for the sake of disarming the hostility of the planters to his enlightened views» [algo que no piensa con el único objeto de desarmar la hostilidad de los hacendados hacia sus ilustradas opiniones] (citado en Luis [1990) 38). Madden elogió altamente a Suárez y Romero ya que: «[i]n this little piece of the Ingenio [sic] there is a minuteness of description and closeness of observation and a rightness of feeling that I have not often seen surpassed». [«En esta obrita del Ingenio hay una minuciosidad en la descripción, una firmeza de observación y una rectitud de sentimiento que no he visto con frecuencia superadas»]. (Del Monte [1930], 4: 85, 83).

Pasando de repente de la crítica literaria a temas más mundanos, Madden altera el tono de su carta al referise a los informes parlamentarios, para criticar la hipocresía de la clase criolla. Contra la opinión del anterior comisionado, Mr. Mc Cleay, quien sostenía que «los propietarios criollos eran hostiles al comercio de esclavos,» declara, en cambio, que solamente se convencería de que están en contra de la trata cuando se nieguen a comprar «negros bozales»; es decir, esclavos importados directamente desde África (Del Monte [1930] 4: 8485). En otra vuelta retórica de la carta, Madden vuelve al juicio valorativo sobre la novela de Suárez y Romero, pidiéndole a Del Monte que le enviara la segunda parte que le faltaba, ya que, a modo de conclusión y de modo un tanto indiscreto, considera que "the $4^{\text {th }}$ does not seem to end the story» [«la $4^{\text {ta }}$ parece que no termina el tema»] (Monte [1930] 4: 84-85). El hecho de que Madden hiciera tanto hincapié en el punto de vista de la clase hacendada cubana, junto con la firme convicción que había expresado antes acerca del poder persuasivo de la literatura, sugiere que, en el contexto cubano de la época, Madden abogaba por un tipo de literatura propagandística que permitiría airar libremente los fundamentos del programa proabolicionista (Monte [1930] 4: 84). 
2. Las «Escenas de la vida privada en la isla de Cuba» y el «tiempo de la nación»

La narrativa de Tanco, de hecho, está saturada de este tipo de retórica; es decir, una retórica que abiertamente suscita apoyo para la causa abolicionista. Debido a su temprano reconocimiento de la presencia negra en Cuba y su enérgica denuncia a los estragos causados por el sistema colonial, la narrativa antiesclavista de Félix Tanco es la más significativa de esta tradición. A pesar de que él mismo declara que «la idea de escribir estas Escenas cubanas [...] me la calentó y fecundó el maldito Balzac con las suyas francesas» (Carta a Del Monte, 20 agosto, 1838; Del Monte [1957] 7: 114), los relatos de Tanco se acercan a los postulados deterministas de un naturalismo a la Emile Zola. Esto se debe al estilo directo de representar la corrupción de la vida moral de la sacarocracia y, al igual, a la agresiva crítica a una sociedad fundada en el trabajo esclavo (Cruz 104-105; Hernáldez-Morelli 75). De acuerdo a su "poética cultural» a favor de la integración racial en Cuba, expuesta en el prólogo a «El niño Fernando,» relato conocido en las letras cubanas como «Petrona y Rosalía,» Tanco articula el discurso más integrador de la identidad nacional cubana, basada en una ética de igualdad racial ${ }^{11}$.

Es más, el tono excesivo, casi agresivo, de sus relatos, contrasta con el estilo más mesurado de los escritores habaneros, quienes, como en el caso de Suárez y Romero, se cubrían del manto del romanticismo para moderar, o al menos intentar suavizar, las dramáticas consecuencias de la trama amorosa (en Francisco, el suicidio del protagonista y la ruina de Dorotea). En el caso de Tanco, está claro que su distancia de La Habana y la recurrente práctica del castigo corporal infligida a los esclavos en los ingenios matanceros, unida al fenómeno frecuente de las rebeliones de esclavos en esa provincia, tuvo un impacto directo en su conciencia de escritor, e influyó hasta el tono mismo de sus relatos. Los historiadores documentan que, a mediados del siglo diecinueve, la región Matanzas/Colón se había convertido en una de las zonas más importantes de la expansión azucarera (Leví Marrero, Moreno Fraginals). Sin lugar a dudas, el testimonio directo con las realidades cotidianas y condiciones de trabajo en los campos de caña tiene que haber incremen- tado la conciencia ética del escritor, quien lo traduce en un idioma artístico no solo altamente realista, sino al borde del naturalismo o determinismo. En contraste con el estilo romántico de Suárez y Romero, Tanco hizo un llamado de atención; mejor dicho, escribe un manifesto, al clamar por la necesidad de manejar realísticamente las «escenas,» género con el cual designaba tanto la brevedad como el efecto estético de sus relatos, que los convierte en retratos impactantes y directos de la vida cotidiana. Es más, aquí Tanco expone su teoría de la literatura basada en cuadros nacionales que revelarían, por medio de «escenas» cortas y de gran intensidad emotiva, las verdaderas «costumbres» del país ([1957] 7: 114; Bueno 176; Méndez Rodenas, [1998] 95). Si bien la clásica Cecilia Valdés de Cirilo Villaverde estrenará la peculiar combinación entre el cuadro de costumbres, descripción, y diálogo, produciendo una mezcla híbrida del romanticismo y realismo, y logrando la novela fundacional cubana por excelencia (Luis [1990] 25, 100-119; Méndez Rodenas, [2002] 53-54, 70-71), Tanco va más allá del tardío romanticismo de Villaverde por el uso idiosincrático del lenguaje.

Salpicadas todas con el idiolecto propio de sus personajes, las «escenas» representan el primer intento de reproducir (imitar) el habla híbrida de sus personajes, rasgo en el que el autor ponía gran orgullo. «En mis Escenas de la vida privada que ahora te remito, verás mucho diálogo, y que el autor habla lo indispensable. Cada persona usa su lenguage particular: nada de bozalismo: mis negros hablan el castellano clarito como lo hablan realmente los criollos», escribe Tanco, no sin criticar, de paso, la tendencia a «fantasear» nombres, y afirmar, a la vez, su práctica de incluir «los nombres comunes entre nosotros» (en Del Monte [1957] 7: 113). El uso de idiolectos africanos influiría tanto en el desarrollo del vernáculo nacional como en el desarrollo posterior de la literatura cubana ${ }^{12}$.

De acuerdo con las ideas estéticas de Domingo Del Monte, quien favorecía y promulgaba el estilo realista heredado de Balzac, Tanco tituló el primer relato (hoy en día el mas conocido) «Petrona y Rosalía», y le pasó juicio en términos hiperbólicos: «Es mi cuento una pintura tan horriblemen. ${ }^{\text {te }}$ verdad [era] de nuestra sociedad y de nras costumbres privadas, que mas no puede ser (Del Monte [1957] 7: 113; én-
11 Para una amplia discusión sobre las poéticas culturales de Tanco, véase $\mathrm{mi}$ ensayo, "Tropics of Deceit.»

12

El uso de la lengua vernacular hace de Tanco un precursor de Guillermo Cabrera Infante y Nicolás Guillén, escritores que también captaron el habla cubana tanto en prosa como en poesía.

El abolicionismo transnacional cubano: los relatos antiesclavistas de Félix Tanco y «el tiempo de la nación"

ADRIANA MÉNDEZ RODENAS 


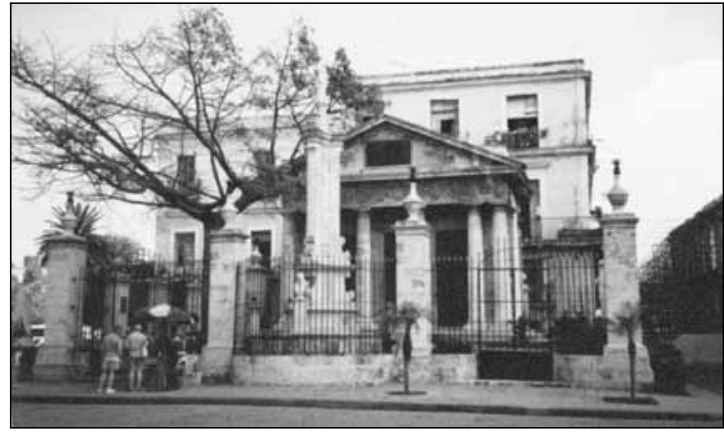

El Templete. Plaza de Armas. La Habana. Fotografía de José Gomariz.

13

Me refiero al ya clásico estudio de Doris Sommer, Foundational Fictions: The National Romances of Latin America. Sugiero, no obstante, que las pasiones interraciales que afloran en el ciclo de narrativa antiesclavista cubana rebasa el marco nítidamente propuesto por la autora, que presupone, en el fondo, un «matrimonio feliz» entre diversas clasas sociales, grupos étnicos o razas, integrados armónicamente adentro del espacio de la nación. Como lo muestra la narrativa de Tanco, el contexto cubano fomenta la violencia $y$ la contradicción como factores intrínsecos al sistema esclavista y colonial que regía los destinos de la isla.

El abolicionismo transnacional cubano: los relatos antiesclavistas de Félix Tanco y «el tiempo de la nación"

ADRIANA MÉNDEZ RODENAS fasis propio; ortografía del autor). En efecto, Tanco quiso forjar un lenguaje estético que forzara los límites del realismo. Quizás fue el extremismo de su visión lo que lo llevó a lamentarse amargamente de que el tríptico narrativo nunca iba a ver la luz del día en Cuba: «Ya se supone que esto no es para imprimirse entre nosotros, $\mathrm{y}$ tal es mi pena» (Del Monte [1957] 7: 114; citado en Bueno 176).

La tendencia naturalista de los relatos antiesclavistas de Tanco quizás explique por qué se incluyeron en el famoso álbum entregado a Madden, junto con otros textos más cercanos a una estética romántica, como la novela arriba comentada de Suárez y Romero (HernáldezMorelli 77). Indudablemente, tanto «El niño Fernando» de Tanco y Francisco de Suárez y Romero giran en torno a una trama parelela; es decir, ambos canalizan la crítica al sistema esclavista por medio de un romance familiar, de acuerdo a las «ficciones fundacionales» de la época ${ }^{13}$. Pero las semejanzas terminan aquí, al surgir diferencias fundamentales de enfoque y de lenguaje entre los dos escritores. A nuestro juicio, la cruda realidad que se desprende de la narrativa de Tanco se aparta de los postulados de la estética delmontina; inclusive rompe con este modelo, al querer mostrar, no tanto un cuadro totalizante (en el sentido de integrador) de la sociedad de la época, de acuerdo al modelo balzaciano, sino, todo lo contrario, una visión fragmentada de una sociedad dividida en lo profundo por raza, clase, y género (aunque estas categorías de la crítica no hacen justicia al efecto terrible, desgarrador, de la narrativa del matancero). De acuerdo a algunos críticos, los escritores decimonónicos utilizaron el sentimiento como idioma literario ya que el nudo erótico podría escapar la censura y servía también para articular una respuesta, aunque reprimida, contra una sociedad esencialmente injusta (Schulman 1082). En el caso de Francisco, no es únicamente el esclavo quien está atrapado en una «trama llena de amor frustrado» (Schulman 1082), sino que, más significativo todavía, se invierte el código de valores de la sociedad esclavista, al desmontar el poder del amo sobre la vida afectiva de la esclava (Luis [1990] 46).
Aquí la trama sentimental se dirige a suscitar la simpatía del lector, táctica quizás más eficaz que una denuncia directa (Luis [1990] 46). Como el miembro «disidente» de la tertulia delmontina, Tanco fue mucho más lejos que sus contemporáneos al denunciar las consecuencias tanto sociales como psicológicas de la esclavitud, como espero mostrar en lo que sigue en una lectura atenta del único relato que nos queda del álbum perdido de Domingo Del Monte.

\section{3. «Un niño en La Habana»: entre lo priva- do y lo público}

Entre junio y agosto de 1838, Tanco escribió las «Escenas de la vida privada en la isla de Cuba», compuesta de tres partes interrelacionadas entre sí aunque formando una unidad narrativa (Lewis Galanes 262). La primera, conocida como «Petrona y Rosalía» en la historia literaria cubana, se cambia al más desabrido título de «El niño Fernando». El cambio puede sugerir que el eje del relato no era tanto la díada madre/hija, sino el petulante y dominante hijo criollo cuya lujuria arruinó a la desafortunada Rosalía de la misma manera que el padre había destruído a su madre Petrona una generación anterior. El segundo relato, titulado «El hombre misterioso,» cuyo título también se cambió a «El cura,» ofrece un retrato escandoloso de los sacerdotes que merodeaban por el campo; éste se incorporó al álbum de Del Monte (Lewis Galanes 264). Ciertamente, Tanco lo consideró el más representativo de todos sus relatos, ya que hincó en este texto todas sus esperanzas de tocar, al fin, al corazón mismo de la sacarocracia, para de ahí rodar abajo la pirámide social, hasta afectar a todos los sectores pensantes de la sociedad cubana. Escuchemos, entonces, las ambiciones del atormentado matancero:

Yo he querido y quiero escribir para los alcances del pueblo cubano: quiero que me entienda cualquier hombre ó muger de nro vulgo, un mayoral, un montero, un negro criollo, un negro ladino, una negra mondonguera, \&a, pero quiero que me entienda igualmente un marques, un conde, un abogado, un médico, un comerciante, \&a. (Del Monte [1957] 7: 116; ortografía original; citado en Bueno 176).

Lamentablemente, el público a que estaba destinado «El hombre misterioso» nunca llegó a conocer las intenciones del autor, ya que 
el relato no se conservó hasta nuestros días. Sin embargo, un cuento titulado «Un niño en La Habana,» mini-relato de solamente un par de páginas, sí se rescató íntegro del álbum de Del Monte (Hernáldez-Morelli 73, 76). Igual que «El niño Fernando», el relato pretendía mostrar el declive moral de la sociedad cubana (Luis [1990] 51). A diferencia de los otros relatos de Tanco, ambientados en el campo o en el cañaveral, «Un niño en La Habana» se adentra en el hogar de la sacarocracia para mostrar un retrato psicológico de un amo de esclavos en ciernes; es decir, en vez de concentrarse en personajes adultos corruptos por el sistema - como en «Petrona y Rosalía»- el relato nos presenta el cuadro interior $-\mathrm{el}$ alma- de un niño que ha perdido la inocencia prematuramente. En breve, «Un niño en $\mathrm{La}$ Habana» dramatiza cómo la esclavitud distorsiona el tránsito psicológico que normalmente ocurre en la niñez, ya que el protagonista ha convertido en adulto prematuro, pues carece de la virtud esencial de la niñez: la inocencia.

La crítica ha señalado la estructura diegética del cuento: un diálogo entre un narrador femenino de voz anónima a quien le toca articular la carga ideológica del relato y «un igualmente anónimo niño de cinco años» (HernáldezMorelli 74; López Cruz 105; Luis [1990] 51). A pesar de la sencillez de la trama - durante una conversación después de la cena en casa de un hacendado criollo, una mujer ${ }^{14}$ se dirige al niño, y le pregunta si le gusta el ingenio de su padre (Hernáldez-Morelli 75), el efecto psicológico del relato se comunica poderosa y enfáticamente. El «espécimen» narrativo de Tanco no solamente revela el grado de corrupción al cual han llegado sus padres (quienes, por lo demás, permanecen ausentes a lo largo del relato), sino, más dramáticamente, el hecho de que la misma decadencia y subversión de valores la hereda la próxima generación sin cambio aparente ni posible (Hernáldez-Morelli 73-74).

En el cuento, el niño, cuyo anonimato sugiere que funciona como prototipo, ya se ha condicionado a la mentalidad racista que caracteriza al padre como amo de esclavos (Hernáldez-Morelli 74). Publicaciones periódicas como La Moda ó Recreo Semanal del Bello Sexo, destinadas principalmente a un público femenino, proponían que eran las madres las responsables de la educación moral de los hijos, o, por lo contrario, y tal como se ve en Cecilia Valdés, la madre consentidora criolla era la principal responsable de «la degeneración de sus hijos» (Hernáldez-Morelli 74). Es por eso que " "Un niño en La Habana" parecería una inversión de ese esquema presente en la casi totalidad de las obras antiesclavistas del período» (Hernáldez-Morelli 74). En contraste, en «Un niño en La Habana», la madre se mantiene ausente del todo, a tal grado que la anónima mujer figura como madre simbólica en su afán por corregir las costumbres corruptas del niño e impedir el derrumbe moral de la nación (Luis [1990] 51). Tanco resalta la orfandad moral y espiritual de un niño, «orfandad casi arquetípica de ese niño cruel y voluntarioso que está llamado [...] a ser un esclavista»; a la vez, la voz de la narradora hace eco del didactismo de los escritores delmontinos (Hernáldez Morelli, 74-75).

Volvamos al diálogo que constituye el meollo del relato. En su función de guía moral o sustituta materna, la narradora repite la obsesión contra el sistema esclavista que compartían Tanco y los otros miembros de la ilustrada tertulia delmontina; al menos, parece adecuarse a la corriente que los enlazaba al más controversial de los abolicionistas británicos, David Turnbull. Ansiosa por saber si al niño le gusta el ingenio, la «Señora» le interroga con cierta tenacidad acerca del aspecto más urgente del imaginario decimonónico cubano: el agobiante asunto del castigo corporal: $«-Y$ ¿allí se castiga? ¿A ti te gusta ver castigar?» La respuesta lacónica, casi automática, del niño es que sí: «-Alli sí se soba [...] á los negros, y á las negras también, porque son muy malos.» La práctica de sobar o «azotar,» se aceptaba como norma en las zonas conocidas como «Cuba Grande», donde se erigían las torres de los ingenios mecanizados o la gran «factoría,» en Matanzas y el resto del occidente de Cuba. Según el dialecto local, sobar designaba de modo eufemístico el castigo físico infligido a los esclavos por el mayoral. El relato hace evidente el vínculo entre la expansión del azúcar - «me gusta mucho porque hay mucha azúcar»-; el miedo de la clase oligarca a las rebeliones de esclavos, y el imperativo de «disciplinar y castigar» - para evocar el famoso epíteto de Michel Foucault - a una fuerza laboral agotada y ya lo suficientemente explotada. La violencia intrínseca a la plantación azucarera se asocia simbólicamente al sistema patriarcal, ya que es el padre - significativamente, el padre ausente- quien funge como amo del
14 Aunque la mayoría de los críticos comentan que se trata de una mujer mayor, calificada un tanto peyorativamente de «matrona» (Hernáldez Morelli, 74), no hay nada que indique la edad exacta de la narradora excepto su sabiduría e inquietud moral.

El abolicionismo transnacional cubano: los relatos antiesclavistas de Félix Tanco y «el tiempo de la nación"

ADRIANA MÉNDEZ RODENAS 


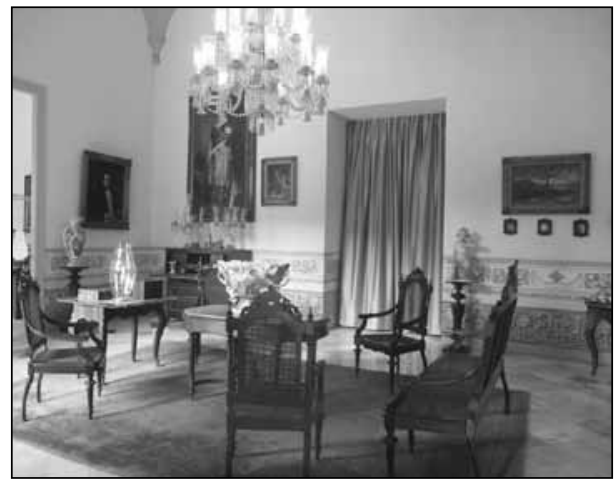

Museo de la Ciudad, Palacio de los Capitanes Generales. Fotografía de Adriana Méndez Rodenas. ingenio (todas las citas provienen de Hernáldez-Morelli 76, 75). La ausencia del padre en este relato se relaciona con la igualmente oculta figura del padre en Cecilia Valdés, cuya culpa se esconde detrás de las apariencias; en el clásico de Villaverde, es el ocultamiento del «Nombre-del-Padre»y, por tanto, del verdadero origen del lazo filial que une a Cecilia y Leonardo lo que desemboca el vínculo incestuoso, y, de ahí, conduce al trágico final (Méndez Rodenas, [2002] 53-71).

El punto climáctico del relato ocurre simultáneamente con el quiebre del diálogo, cuando, al responder a la protesta de su interlocutora acerca del mal intrínseco que representa cualquier acto de crueldad física, el niño ecuánime y cínicamente lo justifica, ya que niega impunemente la humanidad de los esclavos:

[...] á los negros si se les puede sobar: á los bueyes también se les soba cuando no quieren dar vueltas en el trapiche.

-Pero, bien, los bueyes son otra cosa: los negros son lo mismo que tú.

-No Señora los negros no son lo mismo que yo sino como los bueyes y los cochinos, y siempre es menester estarlos sobando. (Hernáldez-Morelli 77)

A continuación, el niño ilustra la espantosa práctica diciendo que él tiene «uno chiquito, que es muy majadero, y le voy a decir a mi papá que lo mande para el injenio, y le diga al mayorlal que le dé chucho» (Hernáldez-Morelli 77). A muy temprana edad, el protagonista parece haberse convertido, por imitación y el peso del ambiente, en un ser insensible al sufrimiento de los otros; una especie de «monstruo» psicológicamente fracturado. Horrorizada al escuchar tal amenaza de la boca de un niño, la narradora le presenta un cuadro del infierno parecido al ingenio del padre, solo que invierte los papeles de víctima y de victimario (Hernáldez-Morelli 77).

-Pues bueno, le dije yo entonces indignada. Dios no querrá si tú eres tan malo y te llevará para el infierno, en donde hay muchas pailas como las calderas del injenio de su padre, y allí echan á la jente mala, y luego vienen muchos diablos, con las uñas muy largas, y con látigos de candela siempre, siempre están dando boca-abajos allá á los que dan boca-abajos acá. (Hernández-Morelli 77)

Si a los esclavos los castigan en el infierno terrenal, el ingenio, al niño lo castigarán en el infierno transterrenal (Luis [1990] 51); insinúa así la narradora que lo que pasa abajo, se repetirá arriba en un ciclo sin fin. El binarismo de la imagen no podría ser más elocuente, mientras que el tono hiperbólico resalta la carga alegórica del relato. A manera de un drama medieval, la imagen infernal de la factoría, término con que Moreno Fraginals designa al tipo de ingenio mecanizado que requería un número cada vez más desproporcionado de esclavos y cuya expansión coincide con la trata ilegal (I, 170, 278), dibuja claramente la distorsión de la sociedad esclavista cubana al igual que subraya el fin didáctico del relato.

Dentro de las «Escenas...» de Tanco, «Un niño en La Habana» es quizás la denuncia más despiadada contra la sacarocracia, ya que muestra no solamente cómo el sistema se perpetúa de generación en generación, sino que la mentalidad nociva del dueño de esclavos parece inamovible (Luis [1990] 52; Hernaldez Morelli 75). La misma desesperanza resurge en el desenlace del cuento: «Esto le dije, y el no afligió ni se si me entendería, ó si tendrá el corazón ya tan indiferente, que mi pintura no le atemorizase» (Hernáldez-Morelli 75, 77).

El cinismo del joven interlocutor recuerda el final de «Petrona y Rosalía,» cuando mueren tanto la joven madre esclava y su recién nacido, el final de una secuela de tragedias en ese relato. Al escuchar la noticia de esta muerte, causada por la lujuria doble entre padre e hijo, la pareja de hacendados atina solamente a calcular la pérdida que este desceso significa para sus caudales: «Paciencia! ...se han perdido mil pesos!» (Tanco [1925], 287). El final irónico de «Petrona y Rosalía» muestra la excepcionalidad de Tanco entre el conjunto de escritores asociados con la tertulia delmontina. Al calcular la pérdida de los esclavos únicamente en términos monetarios, el final del relato alude a la manera en que se anunciaba públicamente la compra/venta de carne humana, particularmente en los anuncios incluidos en los periódicos habaneros (Leví Marrero 9: 61). Los historiadores documentan que, entre 1830 y 1841 , el precio de los esclavos bajó debido al influjo creciente de africanos importados (Bergad, 528). El desenlace de «Petrona y Rosalía» enfatiza el impacto económico de la 
trata. Ya que el precio promedio de una esclava era aproximadamente de 316 a 223 pesos, lo que corresponde a un incremento del treinta por ciento (Bergad 528), el precio nombrado en la queja de los hacendados, «mil pesos,» reflejaría casi el doble del «valor de venta» correspondiente a dos mujeres esclavas, de acuerdo al estimado historiográfico del mercado (Bergad 528). En la encuesta de Madden, Del Monte, en cambio, calcula que el costo de una esclava adulta era «[p]oco menos de 18 a 21 onzas de oro,» mientras que un esclavo varón valía «entre 300 a 400 pesos» ([1929] 135). Si «El niño Fernando» condena a la clase hacendada por la avaricia, la lujuria, y la mentira, «Un niño en La Habana» cumple un propósito similar, solo que con una diferencia significativa. Al trasladar el debate público al ámbito privado - ya que el diálogo ficticio no rebasa los confines de la esfera doméstica- eso sirve paradójicamente para circular el mensaje abolicionista hacia la esfera pública, enfatizando, y con mayor insistencia, la denuncia social que el relato encierra. $\mathrm{Al}$ denunciar a la esclavitud como sistema, los relatos de Tanco provocan el mismo de tipo de «revolución afectiva» como la que tuvo $\mathrm{La}$ cabaña del tío Tom de Harriet Beecher Stowe en los Estados Unidos (Hedrick 7). Tanto «El niño Fernando» como «Un niño en La Habana» configuran la estética prescriptiva de Tanco:

Los negros en la Isla de Cuba son nra. Poesia, y no hay que pensar en otra cosa; pero no los negros solos, sino los negros con los blancos, todos revueltos, $\mathrm{y}$ formar luego los cuadros, las escenas, que á la fuerza han de ser infernales y diabolicas; ;pero ciertas, evidentes!» (Del Monte [1957] 7: 51).

No solamente vemos aquí el impuso hacia la integración racial como motriz de la emergente nacionalidad cubana, sino el fundamento de la estética «tremendista» de Tanco. Al obligar al lector a reconocerse en estas escenaslímite, se alista sus simpatías a favor de la causa abolicionista. Escuchamos en el «Son número 6» de Nicolás Guillén el eco de la frase de Tanco «todos revueltos», donde ya la transculturación está en proceso de reconocerse.

A pesar de que la mayoría de los críticos coloca a las obras antiesclavistas bajo un solo rubro, clasificándolas por orden cronológico (Schulman 1084), o proponiendo la pertenencia al círculo de Del Monte como criterio para incluir determinada obra dentro de este

género $^{15}$, la resistencia contra la esclavitud en el siglo XIX cubano no se limita únicamente a la literatura, sino que incluye otros textos que se deben incluir dentro de esta tradición. En ese otro archivo debe figurar el dramático relato «L'évasion» de la Comtesse Merlin, y su más divulgado ensayo, «Les esclaves dans les colonies espagnoles,» que se ajusta al ideario de José Antonio Saco y a su argumento

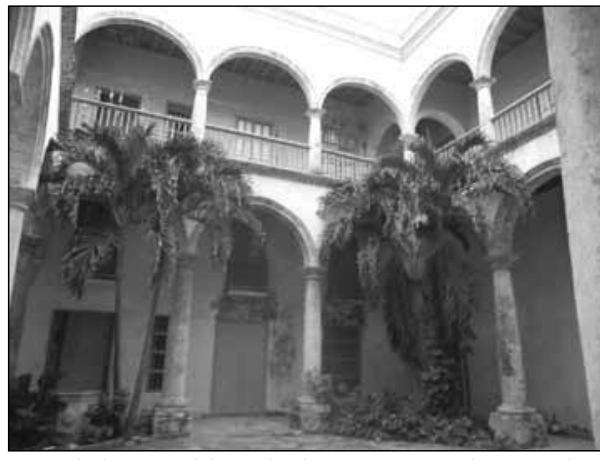

Patio de la casa del conde de Jaruco. La Habana, Cuba Fotografía de Adriana Méndez Rodenas. a favor del cierre inmediato de la trata simultáneo a una abolición progresiva que asegurase un lugar a la población esclava. El ensayo de Mercedes Merlin, que apareció por primera vez en la Revue de Deux Mondes de 1841, es una réplica al libro de David Turnbull, Travels in the West, publicado en 1840, donde el inglés recuenta con alta retórica las crueldades del sistema.

Dentro del mismo archivo habría que incluir las «Cartas políticas» escritas por Del Monte para refutar la acusación hecha en contra de él por haber participado en la conspiración y rebelión de esclavos y libertos que supuestamente aconteció en Matanzas en 1844. A modo de autodefensa, Del Monte acrecienta su deseo de ver la abolición de la esclavitud en Cuba, identificando al sistema como «la causa de nuestra opresión política» (Del Monte [1929] 199-200).

Pero ni la apasionada defensa de Del Monte ni tampoco la mirada penetrante de Tanco hacia el interior de la familia de los sacarócratas, pudieron evitar que ambos escritores cumplieran su destino dentro del «tiempo de la nación» ${ }^{16}$. Tanto es así que los sucesos relacionados con La Escalera, la represión por parte de la Comisión Militar de Matanzas en 1844 en contra de una supuesta conspiración entre negros libertos y esclavos, determinó el cierre de la narrativa antiesclavista. A Tanco lo encierran en prisión y lo deportan a Estados Unidos en 1845 (Bueno 174); a la larga, Del Monte sufre la misma suerte, a pesar de la carta que le escribe al diplomático americano Alexander Everett, donde le advierte acerca de una inminente rebelión de esclavos en la isla (García 111-114; Leví Marrero, 83, 95). Este cambio a última hora no salvó a Del Monte de convertirse en punto de ataque. Sospechoso dadas sus relaciones con el (para España) insidioso David Turnbull, y, más, debido al hecho de que el poeta Plácido lo involucró en el complot bajo
15 Luis explica que no incluye a Sab de Gertrudis Gómez de Avellaneda dentro de su estudio porque ella no perteneció a la tertulia delmontina ([1990] $34,258)$. Consideramos que la inclusión de esta autora de la primera novela de tema abolicionista, junto con los escritos de la condesa de Merlin aquí mencionados, amplían la noción, basada en el predominio de autores masculinos, del cánon literario cubano del siglo XIX.

16

Con este término, Homi Bhabha designa la temporalidad alternativa que sustenta el devenir de una nación, en contra de las cronologías exactas de los historiadores (evento=momento); designa asimismo la pauta entre el discurso pedagógico de la nación (ilustrado en la tertulia delmontina) y la dimensión performativa, los fragmentos, trazos, y rastros de la vida cotidiana (199-209).
El abolicionismo transnacional cubano: los relatos antiesclavistas de Félix Tanco y «el tiempo de la nación"

ADRIANA MÉNDEZ RODENAS 
tortura (Leví Marrero, nota \#230, 254; [1929] 190), el Capitán General O’Donnell mandó al líder más prominente de la intelectualidad cubana al exilio. En última instancia, los destinos convergentes entre el abolicionista irlandés Madden, eliminado de su cargo al convertirse en «hombre peligroso» para Gran Bretaña, el inglés David Turnbull, forzado fuera de la isla, y el exilio compartido entre Saco, Tanco, y Del Monte ofrecen una reflexión irónica sobre «el tiempo de la nación».

\section{Bibliografía}

Bhabha, Homi K. «DissemiNation: Time, Narrative, and the Margins of the Modern Nation». The Location of Culture. Londres y Nueva York: Routledge, 1994. 199-244.

Benítez Rojo, Antonio. «Azúcar, poder, literatura». Cuadernos hispanoamericanos 451452 (1988): 195-215.

Bergad, Laird W. «Slave Prices in Cuba, 18401875", Caribbean Slavery in the Atlantic World: A Student Reader. Eds. Shepherd and Beckles. Kingston: Ian Randle, 2000. 527-542.

Bueno, Salvador.»La narrativa antiesclavista en Cuba de 1835 a 1839.» Cuadernos hispanoamericanos 451-452 (1988): 169-186.

Burton, Gera C. Ambivalence and the Postcolonial Subject. The Strategic Alliance of Juan Francisco Manzano and Richard Robert Madden. New York: Peter Lang, 2004.

Del Monte, Domingo. Centón epistolario de Domingo del Monte. Tomo 3 (1836-1838). Ed. Domingo Figarola Caneda. La Habana: Imprenta El Siglo XX, 1926.

- Centón epistolario de Domingo del Monte. Tomo 4 (1839-1840). La Habana: Imprenta El Siglo XX, 1930.

- Centón epistolario de Domingo del Monte. Tomo 7 (1823-1843). Ed. Manuel Isaías Mesa Rodríguez. La Habana: Imprenta El Siglo XX, 1957.

- Escritos. Vol. I. Ed. José A. Fernández. La Habana: Cultural, 1929.

García, Enildo A. «Cartas de Domingo Del Monte a Alexander H. Everett.» Revista de Literatura Cubana 7.13 (1989): 105-148.

Hedrick, Joan. D., editor. The Oxford Harriet Beecher Stowe Reader. Nueva York: Oxford UP, 1999.

Hernáldez Morelli, Rolando. «Noticias, Lugar y texto de "Un niño en La Habana", especimen narrativo inédito de 1837». Círculo 15 (1986): 73-84.
Kutzinski, Vera. Sugar's Secrets: Race and the Erotics of Cuban Nationalism. Charlottesville: University of Virginia Press, 1993.

Lewis Galanes, Adriana. «El Álbum de Domingo del Monte (Cuba, 1838/39).» Cuadernos bispanoamericanos 451-452 (1988): 255-265.

López Cruz, Humberto. «Petrona y Rosalía. Tanco como innovador subversivo.» Revista cultural Lotería 425 (1999): 103-110.

Luis, William. Literary Bondage: Slavery in Cuban Narrative. Austin: U of Texas P, 1990.

- «Juan Francisco Manzano: entre la oralidad y la escritura.» Del Caribe 31 (2000): 33-40.

- «Introducción.» Juan Francisco Manzano. Autobiografía del esclavo poeta y otros escritos. Edited by William Luis. Madrid: Editorial Iberoamericana/Vervuert, 2007. 13-69.

Marrero, Levi. Cuba: Economía y sociedad. Vol. IX. Madrid: Ed. Playor, 1983.

Méndez Rodenas, Adriana. "Tropics of Deceit: Desire and the Double in Cuban Antislavery Narrative.» Cuban Studies 28 (1998): 83-99.

- «Incesto e identidad en Cecilia Valdés: Villaverde y el origen del texto.» Cuba en su imagen: Historia e identidad en la literatura $\mathrm{Cu}$ bana. Madrid: Editorial Verbum, 2002. 53-71.

Moreno Fraginals, Manual. El ingenio. Complejo económico social cubano del azúcar. 3 Vols. La Habana: Editorial de Ciencias Sociales, 1978.

Murray, David R. «Richard Robert Madden: His Career as a Slavery Abolitionist». Studies-An Irish Quarterly Review. Vol. 61, no. 241 (Spring 1972), 41-53.

- Odious Commerce: Britain, Spain, and the Abolition of the Cuban Slave Trade. Cambridge: Cambridge University Press, 1980.

Romeo Fivel-Démoret, Sharon. «The Production and Consumption of Propaganda Literature: The Cuban Anti-Slavery Novel.» Bulletin of Hispanic Studies 66.1 (1989): 1-12.

Schulman, Ivan. "The Portrait of the Slave: Ideology and Aesthetics in the Cuban AntiSlavery Novel.» 1977. Caribbean Slavery in the Atlantic World: A Student Reader. Eds. Shepherd and Beckles. Kingston: Ian Randle, 2000. 1077-1086.

Sommer, Doris. Foundational Fictions: The $\mathrm{Na}$ tional Romances of Latin America. Berkeley: U of Caifornia P, 1991.

Tanco, Felix. «Escenas de la vida privada en la isla de Cuba.» Cuba contemporánea 39.156 (1925): 255-288.

Fecha de recepción: 05/05/2014

Fecha de aceptación: 07/10/2014 